\title{
INTERDISCIPLINARIDADE EM ENSINO DE CIÊNCIAS E DE MATEMÁTICA NO ENSINO MÉDIO
}

\author{
Interdisciplinarity in Science and Mathematics \\ education at High School level
}

\author{
Vanderlei Lavaqui ${ }^{1}$ \\ Irinéa de Lourdes Batista ${ }^{2}$
}

Resumo: Este artigo é resultado de uma pesquisa que se destina a apresentar e fundamentar elaborações de propostas para a prática de ensino interdisciplinar no Ensino de Ciências e de Matemática na Escola Média, que busquem gerar uma Educação Científica que considere aspectos complexos e relacionais presentes no conhecimento científico e no cotidiano escolar. Inicialmente, estabelecemos uma compreensão a respeito da interdisciplinaridade como prática educativa. Posteriormente, analisamos formas de entendimento dessa temática no âmbito escolar - explicitando os fundamentos educacionais e os aspectos formativos que se destacam em diferentes propostas - e fazemos uma ponderação sobre os condicionamentos na implementação dessa prática.

Palavras-chave: Interdisciplinaridade. Educação científica e matemática. Ensino Médio.

\begin{abstract}
This article is about fundamentals of interdisciplinary education in Science and Mathematics teaching in high school, and is in favor of a scientific education which considers complex aspects of scientific knowledge within the school day. Initially, we established an understanding concerning the interdisciplinary perspective as an educational practice and, later, we analyzed forms of understanding of this theme at school - educational foundations and formative aspects that stand out - and we make a reflection about conditions for the implementation of this practice.
\end{abstract}

Key words: Interdisciplinarity. Scientific and mathematical education. High school.

\footnotetext{
${ }^{1}$ Mestre em Ensino de Ciências e Educação Matemática; Professor da Educação Básica/PR. Toledo, PR. <vlavaqui@yahoo.com.br>

${ }^{2}$ Doutora em Filosofia; professora adjunta, Departamento de Física; Programa em Ensino de Ciências e Educação Matemática (PECEM/UEL), Departamento de Física, Universidade Estadual de Londrina. Londrina, PR.<irinea@uel.br>
}

\footnotetext{
${ }^{1}$ Núcleo Regional de Educação de Toledo Av. Maripá, 4896

Toledo, PR

85.902-060
}

399

Ciência $\stackrel{E}{E}$ Educação, v. 13, n. 3, p. 399-420, 2007 


\section{Introdução}

O Ensino Médio tem sido alvo de constantes discussões na atualidade pois, dentre outros motivos, a presença dos recursos científicos e tecnológicos tem gerado necessidades complementares e diferentes em relação ao ensino propedêutico geralmente praticado. A complexidade dessas questões vem promovendo debates em torno de uma Educação Científica que prepare os educandos para o exercício da cidadania, remetendo-nos a uma reflexão em relação à adoção de práticas interdisciplinares no Ensino de Ciências e de Matemática como uma das possibilidades para a sua melhoria.

A participação de outras disciplinas, nas mesmas condições que as de ciências naturais e matemática, pode contribuir significativamente para a abrangência e profundidade de uma prática de ensino interdisciplinar. Mas uma vez que nossa análise recairá a respeito da necessidade de uma Educação Científica, delimitaremos nossas discussões sobre as disciplinas que tradicionalmente compõem seu núcleo.

Sendo assim, uma questão que merece atenção especial e se apresenta como objeto de reflexão está ligada ao entendimento da interdisciplinaridade como uma ação educativa escolar, de forma que se possam encontrar subsídios para a adoção ou concepção de uma proposta de trabalho que se apresente como geradora de Educação Científica e factível de ser implementada, levando em consideração as condições atuais encontradas na Escola Média. Na literatura de educação em ciências e matemática, o entendimento sobre interdisciplinaridade, e mais especificamente a escolar, é bastante difuso, com diferentes acepções no que diz respeito desde as bases epistemológicas até as implementações pedagógicas factuais.

Essa diversidade de significados pode ser exemplificada por uma breve historização de trabalhos objetivando especificamente o esclarecimento conceitual da interdisciplinaridade. Em dezembro de 1969, constituiu-se em um relatório elaborado por especialistas da Alemanha, França e Grã-Bretanha, reunidos para esse fim. Esse estudo inicial, segundo Fazenda (1992, p. 26), apresentou "a falta de uma precisão terminológica pelo preconceito no trato de questões referentes à integração e pelo desconhecimento mesmo da necessidade de certos pressupostos básicos para a interdisciplinaridade".

Posteriormente, em fevereiro de 1970, um novo encontro de especialistas foi realizado, objetivando esclarecer questões que se mantinham pendentes em relação ao primeiro panorama traçado, e culminou com o estabelecimento de um marco de referência para a busca dos significados de disciplina, multidisciplina, interdisciplina e transdisciplina, apresentando as seguintes definições:

Disciplina - conjunto específico de conhecimentos com suas próprias características sobre o plano do ensino, da formação dos mecanismos, dos métodos, das matérias.

Multidisciplina - justaposição de disciplinas diversas, desprovidas de relação aparente entre elas. Ex.: música + matemática + história.

Pluridisciplina - justaposição de disciplinas mais ou menos vizinhas nos domínios do conhecimento. Ex: domínio científico: matemática + física. Interdisciplina - interação existente entre duas ou mais disciplinas. Essa interação pode ir da simples comunicação de idéias à integração mútua dos conceitos diretores da epistemologia, da terminologia, da metodo- 
Interdisciplinaridade em ensino de Ciências e Matemática...

logia, dos procedimentos, dos dados e da organização referentes ao ensino e à pesquisa. Um grupo interdisciplinar compõe-se de pessoas que receberam sua formação em diferentes domínios do conhecimento (disciplinas), com seus métodos, conceitos, dados e termos próprios.

Transdisciplina - resultado de uma axiomática comum a um conjunto de disciplinas (ex. Antropologia considerada como a "ciência do homem e de suas obras", segundo a definição de Linton) (MICHAUD, 1972 apud FAZENDA, 1992, p. 27).

Em setembro de 1970, em Nice, na França, realizou-se um Seminário sobre a Pluridisciplinaridade e a Interdisciplinaridade nas Universidades, sob o patrocínio da Organização de Cooperação e Desenvolvimento Econômico (OCDE), para discutir questões relacionadas à fundamentação da interdisciplinaridade e sua conceituação com base na colaboração de vários cientistas. No dizer de Santomé (1998), um dos objetivos desse encontro estava fortemente centrado na pretensão de elucidar conceitualmente a interdisciplinaridade e avaliar suas possibilidades, buscando identificar se esta se mostraria com potencial de desenvolvimento de forma efetiva em relação ao ensino e à pesquisa, adaptados frente à evolução do conhecimento e da sociedade. Obteve-se um consenso em relação à crescente complexidade dos problemas enfrentados pelas sociedades modernas.

Perante as variações quanto à nomenclatura e aos conceitos utilizados para definir a interdisciplinaridade surgida a partir de então, apresentaremos algumas das propostas, objetivando localizar as tendências iniciais mais aceitas em relação ao entendimento do que seria uma pesquisa interdisciplinar.

Uma proposta que contribuiu para o esclarecimento da terminologia e dos níveis de hierarquização da interdisciplinaridade foi desenvolvida por Jean Piaget, que apresentou uma distinção de três graus de organização e integração entre as disciplinas:

1. Multidisciplinaridade. O nível inferior de integração. Ocorre quando, para solucionar um problema, busca-se informação e ajuda em várias disciplinas, sem que tal interação contribua para modificá-las ou enriquecê-las. Esta costuma ser a primeira fase de constituição de equipes de trabalho interdisciplinar, porém não implica que, necessariamente, seja preciso passar a instâncias de maior cooperação.

2. Interdisciplinaridade. Segundo nível de associação entre disciplinas, em que a cooperação entre várias disciplinas provoca intercâmbios reais, isto é, exige verdadeira reciprocidade nos intercâmbios e, conseqüentemente, enriquecimentos mútuos.

3. Transdisciplinaridade. É a etapa superior de integração. Trata-se da construção de um sistema total, sem fronteiras sólidas entre as disciplinas, ou seja, de uma teoria geral de sistema e estruturas, que inclua estruturas operacionais, estruturas de regulamentação e sistemas probabilísticos, e que una estas diversas probabilidades por meio de transformações reguladas e definidas (PIAGET, 1972 apud SANTOMÉ, 1998, p. 70). 
Essa perspectiva, considerada no âmbito da possibilidade de realização de uma pesquisa científica interdisciplinar, buscava estabelecer intercâmbios e novas combinações entre as disciplinas, que possibilitassem a superação de limitações ao avanço científico (SANTOMÉ, 1998).

Outra proposta, que buscou estabelecer uma distinção em torno dos conceitos relativos aos níveis de interdisciplinaridade, é a elaborada por Marcel Boisot, que compreende três graus de interdisciplinaridade, assim caracterizadas:

1. Interdisciplinaridade estrutural. Quando as interações entre duas ou mais matérias levam à criação de um corpo de leis novas que formam a estrutura básica de uma disciplina original, que não pode ser reduzida à coordenação formal de suas geradoras, surge uma nova disciplina [...]. 2. Interdisciplinaridade linear. É uma modalidade de intercâmbio interdisciplinar na qual uma ou mais leis tomadas de uma disciplina são utilizadas para explicar fenômenos de outra; mediante alguma redefinição das variáveis e parâmetros, ela seria ajustada ao novo centro disciplinar. A história da ciência constata numerosos exemplos de leis originárias de uma disciplina concreta que foram transferidas e aplicadas com êxito em outra.

3. Interdisciplinaridade restritiva. O campo de aplicação de cada matéria é definido exclusivamente conforme um objetivo concreto de pesquisa e um campo de aplicação específico [...] (BOISOT, 1979 apud SANTOMÉ, 1998, p. 69).

Nessa classificação, a ordem ascendente de interação entre as disciplinas seria organizada a partir da interdisciplinaridade restritiva, seguida pela interdisciplinaridade linear e. posteriormente. pela interdisciplinaridade estrutural, que corresponderia ao maior grau de integração entre as disciplinas.

Outra sugestão de definição e estruturação foi elaborada por Heinz Heckhausen, que fundamentou uma proposta de distinção terminológica embasando-se nas disciplinas empíricas, indicando cinco formas de relações interdisciplinares. De forma sintética, os tipos de interdisciplinaridade defendidos por Heckhausen são:

- Interdisciplinaridade heterogênea - este tipo é dedicado à combinação de programas diferentemente dosados, em que é necessário adquirir-se uma visão geral não aprofundada, mas superficial (poderia dizer-se de caráter enciplopédico); dedicado a pessoas que irão tomar decisões bastante heterogêneas, e que precisarão de muito bom senso. Ex: professores primários e assistentes sociais.

- Pseudo-interdisciplinaridade - para realizar a interdisciplinaridade, partem do princípio que uma interdisciplinaridade intrínseca poderia estabelecer-se entre as disciplinas que recorrem aos mesmos instrumentos de análise. Ex.: Uso comum da matemática.

- Interdisciplinaridade auxiliar - utilização de métodos de outras disciplinas. Admite um nível de integração ao menos teórico. Ex: A Pedago- 
Interdisciplinaridade em ensino de Ciências e Matemática...

gia, ao recorrer aos testes psicológicos para fundar suas decisões em matéria de ensino, como também, colocar à prova as teorias da educação, ou avaliar o interesse de um programa de estudos.

- Interdisciplinaridade complementar - certas disciplinas aparecem sob os mesmos domínios materiais, juntam-se parcialmente, criando, assim, relações complementares entre seus respectivos domínios de estudo. Exemplo: Psicobiologia, Psicofisiologia.

- Interdisciplinaridade unificadora - esse tipo de interdisciplinaridade advém de uma coerência muito estreita, dos domínios de estudo de duas disciplinas. Resulta na integração tanto teórica quanto metodológica. Ex: biologia + física $=$ biofísica (HECKHAUSEN, 1972 apud FAZENDA, 1992, p. 30).

Para categorizar esses níveis de interdisciplinaridade, Heckhausen entende disciplina como uma Ciência e, com base nessa concepção, indica que o termo disciplinaridade significa uma: "Investigação científica especializada de uma matéria determinada e homogênea; exploração que consiste em fazer surgir novos conhecimentos que se substituem a outros mais antigos" (HECKHAUSEN, 1972 apud PALMADE, 1979, p. 221).

Entendendo o conceito de disciplina como sendo uma ciência, a interdisciplinaridade se apresentaria, então, como ciência da ciência, que Fourez (1995) classifica como superciência, na qual a abordagem interdisciplinar estaria isenta da consideração de perspectivas mais particularizadas presentes em diversos pontos de vista disciplinares, com possibilidades de analisar um número muito maior de características de uma dada situação.

No entanto, de acordo com Fourez (1995), ao se tentar construir uma perspectiva universalizada com base na reunião de conhecimentos em torno de uma determinada situação, acaba-se por dar origem a uma nova forma de conceber essa situação, surgindo uma nova disciplina, que buscará construir uma abordagem diferenciada que se mostre mais adequada e abrangente. Verifica-se, então, a não constituição de uma nova representação na forma de superciência universalizada que dissolveria as visões disciplinares.

A classificação apresentada por Heckhausen também é discutida por Japiassu (1976), que indica que os cinco tipos de interdisciplinaridade poderiam ser reduzidos a apenas dois: interdisciplinaridade linear e interdisciplinaridade estrutural. A interdisciplinaridade linear abarcaria as três primeiras formas, caracterizando-se por uma troca de informações sem que, no entanto, venha a ocorrer uma cooperação e reciprocidade de maneira mais efetiva.

Já a interdisciplinaridade estrutural estaria relacionada às duas últimas formas de interdisciplinaridade propostas por Heckhausen, e seria caracterizada por uma maior interação entre duas ou mais disciplinas, sem que haja uma imposição de uma sobre as outras, colocando-se, em comum, conceitos fundamentais e concepções metodológicas que poderiam dar origem a uma nova disciplina.

Assim, é possível perceber que, nessa perspectiva, a interdisciplinaridade acabaria por criar um novo campo de estudos que, mesmo se apresentando como uma forma relevante de possibilitar a resolução de determinadas questões que uma disciplina isoladamente não teria condições de abarcar, buscaria especializar-se, consolidando-se como uma nova disciplina.

Não obstante essas formas de definição e esclarecimentos em torno do conceito de interdisciplinaridade e seus graus de hierarquização, notamos que a proposta mais discutida e 
talvez a mais conhecida seja a desenvolvida por Erich Jantsch, que pressupõe uma forma de conceituar a interdisciplinaridade com base em uma seqüência em que se manifesta um aumento na complexidade das relações, colaboração e coordenação entre as disciplinas (SANTOMÉ, 1998).

Nessa perspectiva, as diferenciações terminológicas propostas por Jantsch podem ser assim resumidas:

1. Multidisciplinaridade: Gama de disciplinas que propõe-se simultaneamente, mas, sem fazer aparecer as relações que possam existir entre elas. [Destina-se a um] sistema de um só nível e de objetivos múltiplos; [mas] sem nenhuma cooperação.

2. Pluridisciplinaridade: Justaposição de diversas disciplinas, situadas geralmente no mesmo nível hierárquico e agrupadas de modo a fazer aparecer as relações existentes entre elas; [destina-se a um] sistema de um só nível e de objetivos múltiplos; [no qual] há cooperação, mas sem coordenação.

3. Interdisciplinaridade: Axiomática comum a um grupo de disciplinas conexas e definida no nível hierárquico imediatamente superior, o que introduz a noção de finalidade. [destina-se a um] sistema de dois níveis e de objetivos múltiplos [no qual há] coordenação procedendo do nível superior.

4. Transdisciplinaridade: Coordenação de todas as disciplinas e interdisciplinas do sistema de ensino inovado, sobre a base de uma axiomática geral. [destina-se a um] sistema de níveis e objetivos múltiplos; [há] coordenação com vistas a uma finalidade comum dos sistemas (JANTSCH, 1972 apud JAPIASSU, 1976, p. 73-74).

Um outro nível hierárquico, presente na proposta de E. Jantsch, está relacionado à denominada disciplinaridade cruzada que, para Fazenda (1992), coloca-se de forma intermediária entre a pluridisciplinaridade e a interdisciplinaridade, e estaria definida como a axiomática de uma só disciplina, imposta a outras disciplinas do mesmo nível hierárquico. Entendemos que essa perspectiva configuraria um domínio de uma disciplina sobre as outras, limitando a capacidade de cooperação e mantendo uma situação de dependência e subordinação.

As propostas apresentadas sugerem definições conceituais para a interdisciplinaridade direcionadas, sobretudo, à pesquisa científica, e fazem isso estabelecendo nomenclaturas baseadas em hierarquias que, de forma geral, orientam-se por ordens de complexidade das relações a se estabelecerem entre as disciplinas científicas.

No entanto, nota-se uma falta de consenso quanto à abordagem teórico-metodológica que poderia ser considerada mais adequada, mesmo com os avanços percebidos nas sistematizações. De certa forma, as perspectivas inicialmente expostas revelam, de forma mais destacada, um esforço de especialistas em procurar construir os pressupostos que possam dar sustentação a um trabalho interdisciplinar, mas que não se originaram de práticas empíricas ou de sistematizações de resultados de pesquisas anteriormente realizadas.

Essa falta de consenso parece ter influenciado as perspectivas interdisciplinares que seriam propostas posteriormente no campo educacional. Assim, as classificações apresentadas 
se mostram relevantes na medida em que revelam uma variação quanto ao entendimento conceitual, que não se apresentou bem definido no sentido de fundamentar a organização e operacionalização de pesquisas científicas interdisciplinares, abrindo a possibilidade de múltiplas interpretações.

Frente a essas considerações, pode se afirmar que, inicialmente, as discussões em torno da interdisciplinaridade foram se desenvolvendo, preponderantemente, em um contexto mais direcionado à pesquisa científica, não enfatizando a prática educativa e tomando, como referência, as demandas ligadas sobretudo às dificuldades encontradas pelo conhecimento científico em fazer frente à excessiva especialização do conhecimento. A esse respeito, Morin (1996, p. 99) afirma que o "progresso dos conhecimentos especializados que não se podem comunicar uns com os outros provoca a regressão do conhecimento geral".

Nosso estudo tem como propósito delinear um entendimento em relação à interdisciplinaridade e suas especificidades na forma de prática escolar - por meio da análise de propostas e experiências, com diferentes acepções, já realizadas com esse objetivo - e, mediante essa fundamentação integrada a referenciais pedagógicos que se mostrem adequados, recomendar uma possibilidade de implementação dessa prática.

\section{Referencial para um entendimento da interdisciplinaridade como prática educativa escolar}

Inicialmente, sistematizaremos os entendimentos quanto à interdisciplinaridade no âmbito da Ciência, distinguindo-a de uma prática orientada para uma ação educativa. Posteriormente, efetuaremos uma análise de propostas e experiências direcionadas à sua implementação no meio escolar. Para tanto, apoiamo-nos em autores como Fourez (1997, 1995), Lenoir (2005, 1998), Batista e Salvi (2006), Santomé (1988) e Klein (1998), dentre outros.

Nos estudos em relação à interdisciplinaridade, parece ser consenso, entre os pesquisadores, a presença de pelo menos dois enfoques principais. Um primeiro está relacionado à busca de uma unidade do saber, à construção de um quadro conceitual cujas preocupações direcionam-se mais enfaticamente ao estabelecimento de uma análise filosófica e epistemológica que visa, especialmente, unificar o saber científico (LENOIR, 1998). É importante salientar que tal unificação tem o cuidado de não produzir efeitos epistemológicos totalizantes.

Para Fourez (1995), trata-se da constituição de uma ciência da ciência, na qual a abordagem interdisciplinar estaria isenta da consideração de perspectivas mais particularizadas presentes em diversos pontos de vista disciplinares, com possibilidades de analisar um maior número de características de uma situação dada.

No entanto, com o objetivo de construir uma perspectiva universalizante a partir da reunião de conhecimentos em torno de uma determinada situação, acaba-se por dar origem a uma nova forma de conceber essa situação, resultando em uma abordagem diferenciada que se mostre mais adequada e abrangente (FOUREZ, 1995). Verifica-se, então, o estabelecimento de uma nova disciplina, e não a constituição de uma representação universalizada que dissolveria as visões disciplinares.

O segundo enfoque articula-se no âmbito de uma perspectiva instrumental (LENOIR, 1998), ou como uma prática particular e específica, direcionada à abordagem de questões relacionadas à existência cotidiana (FOUREZ, 1995). Nessa abordagem, as análises interdisci- 
plinares nutrem-se de saberes que se mostrem pertinentes e aplicáveis a situações problemáticas concretas.

Essas formas de abordagem derivam de perspectivas culturais distintas. O primeiro enfoque identifica-se mais fortemente com características européias continentais, ao passo que o segundo liga-se à tradição anglo-saxônica. Na avaliação de Klein (1998), os modelos europeus têm sido importantes no pensamento a respeito da interdisciplinaridade, mas as ações mais concretas e com maior variedade de exemplos estão relacionadas à perspectiva instrumental. Entretanto, para além das discussões em torno de um ou outro ponto de vista, há uma convergência entre os pesquisadores no sentido de manter esses enfoques nas discussões quanto à interdisciplinaridade escolar.

O entendimento dessas perspectivas é relevante para uma compreensão da interdisciplinaridade como prática escolar, pois revela a existência de pontos de vista diferenciados. Assim, entendemos que algumas questões importantes necessitam ser esclarecidas para se abordar a temática quando tomada como uma ação educativa: a distinção entre a interdisciplinaridade na pesquisa científica e na Educação Escolar; a compreensão dos fundamentos teórico-metodológicos de propostas que objetivam a implementação dessa prática no meio escolar, e a compreensão das características específicas da interdisciplinaridade escolar.

Considerando essas demandas, temos a interdisciplinaridade relacionada ao estabelecimento de distinções entre a interdisciplinaridade na pesquisa científica e a direcionada ao processo educacional, pois, dentre outras particularidades, a concepção de disciplina escolar apresenta significados diferenciados em relação à concepção de disciplina científica, conforme discutiremos a seguir.

Adicionalmente, as funções e os objetivos que se pretendem alcançar a partir da implementação de uma prática interdisciplinar da pesquisa científica também diferem sensivelmente dos objetivos que se pretendem atingir na adoção da interdisciplinaridade na perspectiva escolar.

Uma forma de diferenciação entre práticas interdisciplinares presentes na pesquisa científica e na Educação Escolar, que corrobora nossa forma de entender essa questão, pode se encontrada em Lenoir (1998) que, com base em pesquisas que se dedicaram à análise de disciplinas escolares e científicas, indicou alguns aspectos característicos diferenciadores, quais sejam: as finalidades a que se destinam; os objetos de estudo; as modalidades de aplicação; o sistema de referência e as conseqüências que produzem, ressaltando distinções importantes conforme iremos discorrer.

Constituindo-se num dos principais parâmetros que possibilitam uma visualização de características específicas em cada uma das formas de conceber a interdisciplinaridade, a questão das finalidades assume um papel de grande relevância, pois permite que se delineiem as funções assumidas no âmbito de cada perspectiva.

De acordo com Lenoir (1998, p. 52), a interdisciplinaridade científica apresenta, como finalidade, "a produção de novos conhecimentos [científicos] e a busca de respostas às inúmeras necessidades sociais", ao passo que a interdisciplinaridade escolar apresenta, como principal finalidade, a "difusão do conhecimento [...] e a formação de atores sociais", criando condições para a promoção de um processo de integração de aprendizagens e conhecimentos escolares.

Como forma de possibilitar que essas finalidades possam corresponder a uma prática interdisciplinar no âmbito escolar, dentre outras ações características, faz-se necessário colocar em prática condições apropriadas para se promover e sustentar o desenvolvimento de 
processos integradores e a apropriação dos conhecimentos como produtos cognitivos por parte dos alunos, requerendo, para tanto, uma organização dos conteúdos escolares sobre os planos curriculares, didáticos e pedagógicos (LENOIR, 1998).

Em relação ao objeto de estudo presente em cada uma das perspectivas de interdisciplinaridade - científica e escolar - pode-se perceber que estes diferem quanto à concepção de disciplina. A visão de disciplina científica está intimamente relacionada a um conjunto de conhecimentos bem específicos e que apresenta sua lógica de estruturação interna, com a utilização de métodos próprios de investigação, destinando-se a fazer avançar, por meio das pesquisas, o conhecimento em uma área específica.

Por outro lado, uma disciplina escolar, mesmo que utilize conhecimentos advindos das disciplinas científicas, não se apresenta como cópia daquelas e, também, não é apenas o resultado de uma transposição didática (LENOIR, 1998), mas se coloca como uma forma propícia a que os estudantes venham realizar a aquisição de conhecimentos específicos e outras formas de saber que ajudem a eles a se desenvolverem nos aspectos cognitivos, afetivos e sociais, dentre outros.

Por sua vez, a diferenciação entre as modalidades de aplicação pode auxiliar na compreensão em relação aos objetos de estudo da interdisciplinaridade científica e escolar, pois a modalidade de aplicação da interdisciplinaridade científica está direcionada à pesquisa e apresenta o conhecimento científico como referência, ao passo que a modalidade de aplicação da interdisciplinaridade escolar implica fundamentalmente a idéia de ensino, de formação do aluno, e seu sistema de referência está centrado, então, no aprendiz e em sua relação com o conhecimento (LENOIR, 1998).

Quanto ao sistema referencial, a interdisciplinaridade científica procura um retorno à disciplina na qualidade de Ciência, distinguindo-se, então, da perspectiva apresentada pela interdisciplinaridade escolar, que busca um retorno à disciplina como um saber escolar, não se restringindo às ciências.

Como último parâmetro indicado por Lenoir (1998, p. 52) para a análise comparativa, tem-se que as consequiencias advindas do desenvolvimento da interdisciplinaridade científica produzem resultados diferenciados em relação à interdisciplinaridade escolar. Assim, se por um lado a interdisciplinaridade científica pode conduzir ao surgimento de novas disciplinas e ao desenvolvimento de realizações técnico-científicas, por outro, a interdisciplinaridade escolar conduz ao "estabelecimento de ligações de complementaridade entre as matérias escolares".

Esses aspectos distintivos em relação às práticas interdisciplinares, no âmbito científico e escolar, fornecem a visualização de algumas características relevantes da interdisciplinaridade escolar que se colocam como um dos subsídios para orientar a articulação de uma proposta pedagógica interdisciplinar. Uma proposta que objetiva atender algumas das demandas presentes na Educação, no Ensino de Ciências e de Matemática na Escola Média, notadamente a geração de uma Educação Científica que permita aos educandos uma interpretação predominantemente relacional dos conhecimentos presentes nas diversas disciplinas.

\section{A interdisciplinaridade no âmbito escolar}

Os estudos e pesquisas que buscam fundamentar a introdução de práticas interdisciplinares no âmbito escolar também apresentam características específicas e, muitas vezes, des- 
tinam-se a atingir objetivos educacionais diferentes. Dessa forma, a interdisciplinaridade escolar necessita estar fundamentada em pressupostos que indiquem uma orientação epistemológica ao processo, de forma a permitir um delineamento quanto aos objetivos educacionais e outros aspectos formativos que se pretende que os educandos venham a desenvolver.

Com esse enfoque, apresentaremos e discutiremos propostas que procuram justificar e embasar a adoção de práticas interdisciplinares direcionadas à Educação Escolar, como as defendidas por Batista e Salvi (2006), Fourez, Englebert-Lecompte e Mathy (1997), Santomé (1998), a experiência da Secretaria de Educação da Cidade de São Paulo no período de 1989 a 1992 e, mais atualmente, o projeto Escola Plural, da Secretaria Municipal de Educação de Belo Horizonte (2002), indicando os aspectos que parecem convergir e as características distintivas que se mostrem importantes.

Visamos construir um entendimento quanto aos principais objetivos, revelados pelas pesquisas, a serem atingidos por meio da implementação de práticas interdisciplinares no Ensino de Ciências e de Matemática na Escola Média. Não obstante, consideramos também relevante abordar possíveis formas de organização de um trabalho interdisciplinar escolar que possa atender a esses objetivos.

Uma proposta de prática interdisciplinar como ação educativa escolar é apresentada por Santomé (1998), que defende a construção coletiva de unidades didáticas integradas - uma forma de trabalho na qual participaria um determinado número de disciplinas, ou mesmo áreas do conhecimento, que elaborariam uma unidade temática em torno de uma situação problemática -, que exigiria a contribuição de diferentes saberes durante um intervalo de tempo relativamente curto.

Essa proposta destina-se a iniciar um processo cujo objetivo maior é a elaboração de um curriculo integrado, que busca

abranger os conteúdos de um determinado número de disciplinas ou áreas de conhecimentos durante um período considerável, pelo menos de um ano letivo, e deve ser planejado de tal forma que não gere lacunas importantes nos conteúdos a serem assimilados pelos estudantes. (SANTOMÉ, 1998, p. 222)

Esse ponto de vista é defendido frente ao argumento de que, em qualquer nível educacional, a coerência do planejamento curricular não se mostra perceptível aos alunos e, muitas vezes, nem mesmo aos professores, tornando difícil qualquer forma de integração entre os conteúdos das diferentes disciplinas.

De acordo com Santomé (1998), a elaboração de unidades didáticas integradas, passíveis de serem implementadas em qualquer nível educacional escolar, constitui-se no desenvolvimento de alguns passos, que, em linhas gerais, podem ser descritos como: diagnóstico prévio; determinação das metas educacionais; seleção do tópico a pesquisar, elaboração de um plano de pesquisa; seleção de recursos e estratégias didáticas e avaliação dos estudantes e da unidade didática.

Uma unidade didática integrada não pretende eliminar ou diminuir a importância das disciplinas, mas busca promover um entendimento dos conteúdos disciplinares em uma perspectiva mais ampla, não necessariamente abrangendo todas as disciplinas ou áreas do conhecimento, mas articulando-as de tal forma que as abordagens disciplinares estabeleçam vínculos que proporcionem o desenvolvimento de ações mais complexas. 
Essa forma de interdisciplinaridade, sugerida com base na elaboração de uma organização curricular integrada, considera que as disciplinas escolares continuariam tendo seu lugar. Entretanto, estas seriam utilizadas na medida em que o problema ou temática abordada exigissem conhecimentos específicos de uma ou outra disciplina, melhorando as possibilidades de implementação em situações educativas em que se tem o intento de promover o estudo e análise de conhecimentos mais específicos, igualmente necessários à formação do aluno.

Outra forma de entendimento da interdisciplinaridade é esboçada por Fourez, Englebert-Lecompte e Mathy (1997), que estabelecem uma fundamentação para o desenvolvimento de uma proposta interdisciplinar no Ensino de Ciências e de Matemática, objetivando promover uma alfabetização cientifica e tecnológica, que, no sentido atribuído por Fourez (1997, p. 23), consiste em "divulgar conhecimentos suficientes para a população de maneira que as decisões dos técnicos possam ser suficientemente compreendidas e também controladas democraticamente".

A justificativa para o desenvolvimento das práticas interdisciplinares é fundamentada de forma mais destacada no questionamento quanto à eficácia das disciplinas do Ensino de Ciências e de Matemática em relação à introdução dos alunos na discussão de questões científicas e tecnológicas, sobretudo relacionadas à necessidade de ensiná-los a utilizar o conhecimento científico e tecnológico em seu cotidiano, seja em relação a questões sociais, individuais ou políticas.

A interdisciplinaridade é descrita por Fourez, Englebert-Lecompte e Mathy (1997), em um sentido restrito, como:

[A] construção de representações do mundo que se encontram estruturadas e organizadas em função de um projeto humano (ou de um problema a resolver), em um contexto específico e para destinatários específicos, apelando a diversas disciplinas, objetivando chegar a um resultado original não dependente das disciplinas de origem (FOUREZ, ENGLEBERT-LECOMPTE e MATHY, 1997, p. 106-107).

Considerando esse entendimento em torno da interdisciplinaridade e defendendo que esta, no âmbito escolar, não se coloca apenas como uma questão de ordem didática, mas também precisa ser situada em função de princípios epistemológicos, ressalta-se que os professores assumam uma forma de representação operacional que possa dar sentido a essas práticas.

Fourez (1997) apresenta, então, um procedimento metodológico denominado Ilhas Interdisciplinares de racionalidade, que orienta as atividades no interior de um trabalho interdisciplinar, constituindo-se na construção de um modelo simplificado, considerado adequado, que utiliza conhecimentos provenientes de várias disciplinas e, adicionalmente, dos saberes presentes na vida cotidiana, indispensáveis ante as práticas concretas (FOUREZ, 1997).

Esse procedimento nos leva a considerar que a interdisciplinaridade é analisada de um ponto de vista restrito e localizado, direcionado a abordar problemas concretos ou noções específicas, buscando estabelecer elos de relação entre o conhecimento científico e tecnológico presente em situações concretas do cotidiano.

No Brasil, uma primeira experiência institucionalizada de implementação de uma prática interdisciplinar escolar, mais efetivamente organizada e colocada em prática, talvez seja a desenvolvida pela Secretaria Municipal de Educação de São Paulo a partir de 1989, e que se 
sustentou por, aproximadamente, três anos, chegando a atingir 180 escolas municipais de primeiro grau e cerca de seis mil e duzentos professores.

Essa proposta direcionou-se ao processo de construção e implementação de um currículo escolar que considerasse as diferentes realidades e contextos específicos de cada escola e tratasse de questões interdisciplinares em sala de aula. A prática interdisciplinar articulou-se no interior de uma concepção de Educação na qual o eixo norteador esteve centrado na concepção de escola popular e democrática, fortemente influenciada pelas idéias de Paulo Freire, que esteve à frente da Secretaria Municipal de Educação durante praticamente todo o período em que o projeto foi desenvolvido.

De acordo com Delizoicov e Zanetic (1993), a implementação dessa prática interdisciplinar objetivou superar o procedimento dominante na forma de se escolher os conteúdos escolares, freqüentemente desvinculados dos aspectos históricos que lhes deram origem e afastados das questões presentes no cotidiano. As escolas, com base em um levantamento da realidade local e com o necessário apoio logístico, poderiam apresentar uma forma alternativa de construção do currículo, pois o estudo de sua realidade indicaria a discussão e o delineamento de questões significativas presentes na comunidade escolar.

A proposta, apesar de abrangente, não foi entendida pelas escolas e pelos professores de maneira uniforme, e os motivos que os levaram a participar do projeto da interdisciplinaridade revelaram algumas distorções. Segundo pesquisa realizada por Sampaio, Quadrado e Pimentel (1994), a maioria das escolas que aderiram ao projeto contava com a adesão de, aproximadamente, setenta por cento de seus professores, mas, em alguns casos, houve escolas em que apenas professores de um turno ou de algumas turmas tiveram uma participação mais efetiva.

Ainda de acordo com essa pesquisa, os motivos que levaram as escolas a participarem do projeto variaram bastante: desde aquelas que já desenvolviam ou procuravam implementar projetos diferenciados no processo de ensino e de aprendizagem, até aquelas motivadas por questões técnicas e/ou financeiras, como, por exemplo: a possibilidade de receberem assessoria de universidades, o acesso a materiais pedagógicos e o recebimento de horas extraordinárias para discussão e planejamento das ações.

Procurando compreender melhor o processo de elaboração curricular que encontrou na interdisciplinaridade uma forma de tornar possível sua implementação, encontramos, em Pernambuco (1993), a indicação de uma seqüência de cinco etapas: levantamento preliminar da realidade local, análise das informações, identificação dos pré-temas geradores, escolha dos temas geradores e planejamento das disciplinas e trabalho pedagógico, que foram utilizadas pelas escolas que participaram do processo.

Por sua vez, tal implementação da interdisciplinaridade em sala de aula foi organizada valendo-se da metodologia dialógica, também fundamentada nos estudos de Paulo Freire, e apresenta-se "como o caminho interdisciplinar de [...] instalar aprendizagem, levando em conta o diálogo e as interações entre todos os elementos do processo e contribuindo para o ir e vir constante entre o real e o conhecimento já elaborado" (SAMPAIO, QUADRADO e PIMENTEL, 1994, p. 63).

De forma sintética, tem-se que, partindo dos temas geradores adotados, sugeridos com base no estudo e análise da realidade da comunidade escolar, buscou-se propiciar a visualização de formas diferenciadas de se ver essa realidade, visando inseri-las em um processo no qual, por meio da interdisciplinaridade, tenham a oportunidade de serem articuladas ao conhe- 
cimento escolar, com o fim de promover o surgimento de uma postura de transformação social.

Outra proposta que defende uma articulação abrangente dos conhecimentos escolares - mas em uma perspectiva transdisciplinar - consiste no Projeto Escola Plural, da Secretaria Municipal de Educação de Belo Horizonte. Esse projeto apresenta como principais aspectos característicos: a reorganização do espaço e tempo escolares; a adoção de fundamentos teóricos que orientam o processo de ensino e de aprendizagem, e a adoção de procedimentos metodológicos fundamentados na Pedagogia de Projetos, como defendida por Leite (1996).

Para sua implementação, a orientação está direcionada para a inserção de Ciclos de Formação, apresentando-os como uma forma de (re)organização do tempo escolar, de maneira que este seja mais flexível e mais longo, redefinindo o processo de seriação por idades homogêneas com base na justificativa de que a multiplicidade de características sociais e culturais presentes no processo educativo implica mais tempo para o desenvolvimento da aprendizagem de conceitos, valores e atitudes (BELO HORIZONTE, 2002).

Quanto ao processo de ensino e de aprendizagem, defende-se que os conhecimentos são construídos a partir de uma estreita relação com os contextos em que são utilizados, sugerindo que as intervenções pedagógicas sejam pautadas em temáticas sociais presentes na contemporaneidade, recomendando a adoção de ações educativas com características globalizantes e transdisciplinares. Esse delineamento implica uma reordenação no seqüenciamento dos conteúdos, tratando-os de forma mais flexível, de acordo com as necessidades derivadas da adequação às experiências sociais e culturais trazidas pelos alunos.

O procedimento metodológico adotado com o objetivo de promover essa perspectiva é a Pedagogia de Projetos (LEITE, 1996). Quanto ao seu desenvolvimento, busca-se organizar os projetos partindo de um assunto que conduza a uma problematização. Esta se coloca como o ponto de partida, chamado de "detonador do projeto", na qual os alunos são convidados a expressar suas crenças, opiniões e conhecimentos sobre um determinado problema em questão, sendo então necessário que a intervenção pedagógica parta dessas impressões e conhecimentos para organizar o projeto a ser desenvolvido.

O segundo momento de desenvolvimento de um projeto esboçado nessa proposta consiste em criar estratégias que possibilitem buscar respostas aos questionamentos e hipóteses admitidas na etapa inicial. Uma característica fundamental desse momento consiste em fazer com que, por meio de pesquisas em materiais bibliográficos e/ou de campo, entrevistas e debates, dentre outras possibilidades, possa-se fazer com que os alunos sejam colocados em situações que os obriguem a confrontar suas opiniões iniciais frente a novos elementos proporcionados pelos conhecimentos presentes nas disciplinas escolares.

O terceiro momento consiste em uma síntese, que se fundamenta na visão em que, durante todo o processo, as percepções e conhecimentos iniciais possam ir sendo substituídos por saberes mais complexos e melhor elaborados, constituindo-se em novas fontes de conhecimentos prévios para outras situações.

Algumas questões que consideramos como limitadoras à implementação dessa proposta no Ensino de Ciências e de Matemática na Escola Média estão relacionadas, sobretudo: à exigência de uma articulação curricular, embasada no desenvolvimento de conceitos em uma perspectiva transdisciplinar; às características das disciplinas escolares do Ensino de Ciências e de Matemática, e à formação dos professores. 
No que diz respeito à forma de organização curricular proposta para o desenvolvimento dos projetos (com a recomendação que o planejamento seja elaborado por meio de conceitos ou questões-chave a serem desenvolvidas durante um ano letivo, por exemplo), está implicada uma reestruturação que se afasta de considerar algumas especificidades presentes nas disciplinas escolares, na medida em que cada disciplina, de forma geral, apresenta uma ordenação lógica de seus conteúdos e uma estruturação diferenciada quanto ao processo de ensino e de aprendizagem.

Assim, mesmo considerando que apenas a perspectiva disciplinar não se mostra suficiente para atender às demandas atuais no Ensino de Ciências e de Matemática na Escola Média, consideramos que uma ruptura que objetiva passar de um extremo a outro, ou seja, de uma prática disciplinar para uma prática que se pretende transdisciplinar, poderia levar a uma série de dificuldades: choques epistemológicos disciplinares, concepções docentes e discentes diferenciadas a respeito da natureza da ciência e das práticas escolares, estrutura no espaçotempo escolar, dentre outros, que, em nosso ponto de vista, inviabilizariam sua implementação efetiva célere, como é a necessidade real.

Outro aspecto relevante diz respeito à formação dos professores, pois estes últimos foram e são formados em uma perspectiva disciplinar. Assim, uma proposta que busque alterar essa forma de trabalho de maneira extrema, direcionando-a para uma prática transdisciplinar, dá origem a fortes reações contrárias e, como a proposta necessita de uma articulação coletiva, esta pode se tornar inviável.

Por fim, um entendimento diferenciado em relação à adoção de práticas interdisciplinares é encontrado em Batista e Salvi (2006), indicando que a prática educativa escolar necessita atribuir maior importância epistemológica ao caráter pluralístico contemporâneo.

Considerando a manutenção de uma estrutura disciplinar, as autoras propõem que, em momentos específicos do trabalho pedagógico, insiram-se momentos interdisciplinares como uma forma de relacionar, articular e integrar os conhecimentos disciplinares no processo de ensino e de aprendizagem, promovendo uma Educação Científica na qual o educando adquira competências para interpretar a complexidade do mundo atual.

Adicionalmente, chamam a atenção para a adoção de enfoques que fundamentem a implementação de práticas interdisciplinares na perspectiva de construção do conhecimento durante o processo de ensino e de aprendizagem, apresentando contrapontos em relação às concepções que buscam aliar a interdisciplinaridade a finalidades unicamente sociais.

A justificativa para esse entendimento deriva de uma análise quanto ao significado relativo da realidade, à inconclusividade e relativismo presentes nas explicações e análises científicas e à presença de elementos contextuais e plurais, buscando superar os limites impostos por posturas deterministas e simplificadoras que dificultam uma compreensão mais profunda da realidade (BATISTA e SALVI, 2006).

$\mathrm{Na}$ visão das autoras, a interdisciplinaridade no ensino não significaria a elaboração de um currículo interdisciplinar, mas sim a inserção de momentos específicos no "amplo ato de ensinar e aprender", pois a realização de um trabalho interdisciplinar se localizaria no interior de um processo que prevê e mantém a adoção de enfoques disciplinares, articulados coerentemente entre o conhecimento disciplinar e interdisciplinar. Compreenderia a construção do conhecimento "junto com o educando, levando em consideração as suas concepções prévias, e [levando-o] a atingir uma alfabetização científica que contemple um recorte episte- 
Interdisciplinaridade em ensino de Ciências e Matemática...

mológico fundamentado na Pós-modernidade e no pensamento complexo" (BATISTA e SALVI, 2006, p. 155).

As análises disciplinares seriam responsáveis pela promoção do conhecimento das especificidades que se mostram necessárias à compreensão da complexidade do mundo, mas, adicionalmente, e em momentos específicos da organização curricular, inserir-se-iam momentos interdisciplinares, com o intuito de promover "uma análise interfacetada, relacional e integradora, na qual o entrelaçamento das partes produz novo significado ao todo" (BATISTA e SALVI, 2006, p. 157).

Partindo da perspectiva de fundamentação centrada na promoção de uma aprendizagem significativa, permitindo a implementação de práticas interdisciplinares na construção do conhecimento durante o processo de ensino e de aprendizagem, e não apenas associando a interdisciplinaridade a finalidades sociais, essa proposta pode se colocar como uma alternativa com potencial de proporcionar a superação da excessiva especialização dos conteúdos presentes nas disciplinas escolares, notadamente no Ensino de Ciências e de Matemática na Escola Média.

Adicionalmente, tal proposta direciona os objetivos educacionais para uma perspectiva cujo processo de ensino e de aprendizagem necessita reconhecer que os conhecimentos científicos, técnicos e sociológicos se apresentam em um processo de profunda interação, contribuindo para que a formação educacional escolar seja inclusiva e emancipatória.

Parece-nos importante ressaltar, como indicam Batista e Salvi (2006), que a dialogicidade entre os conhecimentos disciplinares e a perspectiva interdisciplinar, proposta como um movimento de "idas e voltas", possibilita o desenvolvimento de novas formas de pensar e agir, pois, ao mesmo tempo em que se busca uma integração mais profunda para a compreensão dos conhecimentos, podem-se realizar estudos mais refinados, igualmente relevantes para a formação dos educandos.

Consideramos, então, que a perspectiva de implementação de práticas interdisciplinares no Ensino de Ciências e de Matemática, defendida por Batista e Salvi (2006), coloca-se como uma alternativa, na medida em que localiza a interdisciplinaridade no interior do processo de ensino e de aprendizagem, fazendo com que esta se apresente como uma possibilidade factível dentro dos limites impostos pela dinâmica presente na Escola Média de hoje.

\section{Apreciação comparada de propostas de implementação da interdisciplinaridade escolar}

Analisando alguns aspectos que fundamentam o desenvolvimento de práticas interdisciplinares no âmbito escolar nas propostas anteriormente expostas, identificamos a existência de algumas características distintivas importantes, como: os fundamentos teórico-metodológicos adotados; a função assumida pela interdisciplinaridade e os objetivos educacionais que pretendem atingir.

É possível inferir, por exemplo, que os fundamentos teóricos e os objetivos educacionais que se pretende promover na proposta de Batista e Salvi (2006) e Fourez, EnglebertLecompte e Mathy (1997) possuem diferenças. Assim, a perspectiva interdisciplinar defendida pelas primeiras busca promover uma aprendizagem significativa por meio de um interfacea- 
mento entre as abordagens disciplinares e interdisciplinares, em que os momentos interdisciplinares promoveriam uma reconciliação integrativa dos conhecimentos estudados disciplinarmente.

Por sua vez, os objetivos educacionais que se busca promover na prática interdisciplinar proposta por Fourez (1997) estão direcionados, de forma mais aplicada, à alfabetização cientifica e tecnológica, em uma perspectiva técnico-instrumental, na medida em que privilegiam o estudo de assuntos mais diretamente ligados aos princípios de funcionamento de dispositivos tecnológicos - aparelhos eletroeletrônicos, por exemplo -, visando também que os alunos se posicionem de forma mais autônoma frente a problemas de seu cotidiano.

De maneira mais específica, a alfabetização científica e tecnológica, no sentido atribuído por Fourez (1997, p. 23), propõe-se a "divulgar conhecimentos suficientes para a população de maneira que as decisões dos técnicos possam ser suficientemente compreendidas e também controladas democraticamente". Por sua vez, no entendimento de Batista e Salvi (2006), os estudos interdisciplinares são uma forma de promover o entendimento da pluralidade e da complexidade das relações presentes na atualidade no processo de ensino e de aprendizagem escolares.

No entanto, não é possível afirmar que uma delas pode ser considerada de maior relevância em relação à outra. O que ressaltamos é que os fundamentos e os objetivos educacionais são diferentes e que a opção por uma ou outra perspectiva deve ser entendida e explicitada como uma opção da escola e/ou docentes diante do contexto educativo e dos aspectos formativos que se deseja atingir.

Podemos ressaltar ainda que ambas as perspectivas se colocam como uma opção epistemológica que entende a interdisciplinaridade no âmbito de uma abordagem relacional, pois buscam o estabelecimento de relações de complementaridade, de convergência e de interconexões entre as disciplinas escolares. Assim, de acordo com as necessidades educativas, não parece haver impedimento de que em determinados momentos interdisciplinares haja o desenvolvimento de uma ilha interdisciplinar de racionalidade.

Em uma segunda observação, notamos que os princípios que fundamentam as ações interdisciplinares defendidas por Fourez (1997) e Batista e Salvi (2006) diferenciam-se, individualmente e em conjunto, em relação à experiência de trabalho interdisciplinar desenvolvida pela Secretaria Municipal de Educação de São Paulo e à proposta defendida por Santomé (1998), pois estas últimas visam promover uma articulação de todo o currículo escolar em uma perspectiva interdisciplinar. $\mathrm{O}$ mesmo se pode afirmar quanto à sugestão do Projeto Escola Plural, da Secretaria Municipal de Educação de Belo Horizonte, que objetiva a implementação de práticas transdisciplinares.

Enquanto Fourez (1997) pretende promover a confluência de conhecimentos disciplinares para a resolução de problemas concretos, em um caráter técnico-instrumental, a proposta de interdisciplinaridade da Secretaria Municipal de Educação de São Paulo pretendeu construir uma articulação buscando estabelecer um currículo interdisciplinar total em um referencial de Educação Popular.

Observações semelhantes podem ser inferidas quanto à proposta de Batista e Salvi (2006), que não pretendem promover a construção de um currículo interdisciplinar, mas inserir momentos interdisciplinares no âmbito do currículo disciplinar já existente.

Por sua vez, tomando a proposta de implementação de práticas interdisciplinares defendida por Santomé (1998) e as sugestões de Fourez (1997), percebemos que a elaboração 
de unidades didáticas integradas se propõe a promover a integração dos conteúdos de diversas disciplinas escolares objetivando chegar a um curriculo integrado, enquanto as ilhas interdisciplinares de racionalidade, mesmo exigindo um planejamento inicial por parte de um ou vários professores, podem ser desenvolvidas de forma esporádica no transcorrer do processo educativo.

De um ponto de vista operacional, essa diferença é significativa, pois o planejamento e o desenvolvimento de uma ilha interdisciplinar de racionalidade, admitindo a possibilidade de ser realizada de forma mais esporádica, exige uma articulação menos intensa por parte dos professores. Por sua vez, o planejamento e desenvolvimento de uma unidade didática integrada implica obrigatoriamente um trabalho coletivo entre os professores das disciplinas participantes do currículo por um intervalo de tempo mais longo e com maior profundidade.

Quanto aos aspectos formativos enfatizados, as unidades didáticas integradas direcionam-se mais intensamente para uma formação em que os conteúdos curriculares possam ser entendidos pelos alunos de forma ampla, destacando, dentre outros aspectos, o reconhecimento das influências sociais, econômicas e culturais presentes na construção do conhecimento; ao passo que, nas ilhas interdisciplinares de racionalidade, os objetivos formativos estão, na sua formulação inicial, direcionados à geração da alfabetiz̧ação científica e tecnológica, constituindo-se primordialmente no estudo, sob diferentes enfoques, de questões técnico-científicas.

Assim, os princípios teórico-filosóficos e as sugestões metodológicas implicam a formação dos educandos tomando como referência diferentes perspectivas de sociedade; e o estudo dessas formas de compreender a interdisciplinaridade escolar se apresenta como um elemento e um instrumento importante para a implementação de ações dessa natureza no Ensino de Ciências e de Matemática, pois, mesmo com as propostas existentes, notamos que, de forma geral, essa prática não se faz presente de forma mais significativa no cotidiano das Escolas de Ensino Médio.

Considerando inicialmente as unidades didáticas integradas, verificamos que estas exigem uma articulação bastante ampla e que encontraria fortes limitações, sobretudo em relação à formação dos professores (notadamente disciplinar) - e à dedicação para o planejamento escolar desses professores (tempo adequado para planejamento e acompanhamento de ações). $\mathrm{Na}$ estrutura atual de organização curricular e administrativa do Ensino Médio, é quase impeditivo o equacionamento do tempo e do espaço escolares de forma amplamente flexível para que se possa planejar e desenvolver adequadamente tal proposta.

Essas objeções poderiam ser direcionadas, de forma semelhante, à implementação, no Ensino Médio, da proposta desenvolvida pela Secretaria Municipal de Educação de São Paulo no Ensino Fundamental, e do Projeto Escola Plural, da Secretaria Municipal de Educação de Belo Horizonte.

Por outro lado, a proposta de elaboração de ilhas interdisciplinares de racionalidade, como um modelo didático interdisciplinar a ser desenvolvido para abordar problemas concretos e do cotidiano, coloca-se como uma possibilidade de implementação de práticas interdisciplinares, pois os professores desenvolveriam trabalhos interdisciplinares de tempos em tempos, fato que diminuiria as limitações quanto às questões de organização do espaço e do tempo escolares adequados para o desenvolvimento da proposta.

No entanto, considerando a importância de se promover uma Educação Científica mais abrangente, deve-se levar em consideração, como indicam Batista e Salvi (2006), a implementação de práticas interdisciplinares que estejam integradas ao processo de ensino e de 
aprendizagem significativos, e que permitam o estabelecimento de inter-relações entre os conhecimentos disciplinares e destes com o cotidiano, de uma forma fundamentada e planejada, a partir do referencial teórico-metodológico da Aprendizagem Significativa.

A promoção dessa perspectiva de ação interdisciplinar implica a adoção de formas de organização do trabalho interdisciplinar e propostas pedagógicas que contemplem modelos didáticos que permitam sua operacionalização. Uma das formas de organizar um trabalho interdisciplinar nessa perspectiva, e que se mostra em consonância com nossa compreensão sobre a temática, é indicada por Lenoir $(2005,1998)$, que entende a sua efetivação como prática educativa em três planos: o curricular, o didático e o pedagógico, de maneira que as ações interdisciplinares se mostrem organizadas coerentemente.

A interdisciplinaridade curricular consiste primordialmente no estabelecimento de ligações de interdependência, de convergência e complementaridade entre as diferentes disciplinas escolares, para que o currículo apresente uma estrutura que possibilite o desenvolvimento de uma prática interdisciplinar.

Um segundo plano da interdisciplinaridade escolar corresponde à interdisciplinaridade didática, tratando do planejamento, da organização e da avaliação das intervenções educativas, uma espécie de intermediação entre a interdisciplinaridade curricular e a interdisciplinaridade pedagógica, objetivando articular e inserir os conhecimentos escolares nas situações de aprendizagem. Por sua vez, a interdisciplinaridade pedagógica caracteriza-se por assegurar a colocação em prática de um ou mais modelos didáticos interdisciplinares no contexto da sala de aula.

Analisando a organização proposta por Lenoir $(2005,1998)$ para os níveis de interdisciplinaridade escolar, percebemos que esta é pensada com base em uma hierarquização que objetiva articular as disciplinas escolares em uma perspectiva que envolve desde a elaboração do currículo, favorecendo uma articulação convergente e interdependente entre elas e mantendo suas especificidades, com um planejamento que implique a elaboração ou adoção de um modelo didático que permita nortear sua implementação e culmine na prática pedagógica dos professores em sala de aula.

Essa forma de organização é resultante de pesquisas, junto a professores do primário no Quebec, Canadá, e estudos da estrutura de organização dos currículos e disciplinas, consistindo em um esforço no sentido de orientar teórico-metodologicamente a realização de práticas interdisciplinares na Educação Escolar. A título de exemplificação, nas pesquisas junto aos professores, dentre outros aspectos, investigaram-se as justificativas indicadas pelos docentes para a adoção dessa prática e os entendimentos a seu respeito. Quanto às justificativas, estas revelaram que os docentes apresentam opiniões que vão desde a adoção de modismos e imposições administrativas até posições que se mostraram como resultado de uma tomada de consciência de sua real necessidade (LENOIR e LAROSE, 1998).

A respeito do entendimento, pelos professores, sobre interdisciplinaridade, constatou-se a presença de uma "confusão discursiva e praxiológica no ensino" (LENOIR e LAROSE, 1998, p. 50), resultante de uma superposição conceitual decorrente de orientações que nem sempre se mostram complementares e, por vezes, são até mesmo opostas.

Podemos exemplificar também, na mesma perspectiva, a elaboração e desenvolvimento de trabalho com projetos que, adaptados à realidade de cada escola, se mostram como uma alternativa em condições de proporcionar momentos interdisciplinares, conforme pode ser encontrado em Batista e Lavaqui (2004). 
A dedicação desta pesquisa ao Ensino Médio mostrou-se relevante pelo fato de poucas ações interdisciplinares estarem, efetivamente, ocorrendo nesse nível. É nele também que o estudante faz a transição de uma disciplina nomeada Ciências para as disciplinas específicas de Biologia, Física e Química. De um momento para outro, os conteúdos científicos tornamse estanques, fragmentados e lineares. A Matemática distancia-se de quaisquer relações empíricas. Essa problemática da organização pedagógica do Ensino Médio pode ser enfrentada com os momentos interdisciplinares, uma forma factível, na estrutura curricular, que promove uma autonomia para a iniciativa de duas ou mais disciplinas que se articulem e integrem em uma prática pedagógica interdisciplinar, mostrando ciências mais próximas, com suas especificidades.

Desse modo, promove-se uma educação científica que prepare o estudante para uma formação profissional inicial que, por ter especificidades, é disciplinar e, ao mesmo tempo, propicia uma formação integrada e autônoma, mediante a aquisição interdisciplinar de uma linguagem e uma cultura científica, para ação do indivíduo aprendiz no mundo.

\section{Considerações finais}

Este trabalho objetivou construir um entendimento sobre a interdisciplinaridade como ação educativa, buscando diferenciá-la da pesquisa, e explicitar a importância dessa conceituação quando da elaboração de uma proposta pedagógica para o Ensino de Ciências e de Matemática na Escola Média, direcionada notadamente a uma real educação científica.

Inicialmente, localizamos perspectivas epistemológicas que fundamentam essa prática, seja na pesquisa científica ou na Educação Escolar, originadas de concepções culturais que valorizam aspectos diferenciados do conhecimento, como aquelas presentes nos países anglosaxônicos e francófonos. No entanto, é desejável que haja uma manutenção desses pontos de vista, evitando o surgimento de posições extremadas, que podem conduzir a uma redução nas possibilidades de atender necessidades geradas em diferentes contextos sociais, econômicos e culturais.

Posteriormente, realizamos estudos que nos permitiram caracterizar e delinear alguns aspectos teóricos essenciais para a implementação de práticas interdisciplinares no Ensino de Ciências e de Matemática no Ensino Médio. Além do estabelecimento de uma base epistemológica, mostrou-se que é preciso estabelecer uma compreensão quanto à adoção da interdisciplinaridade no âmbito pedagógico, pois as diferentes concepções e as perspectivas educacionais que orientam a implementação dessa prática destinam-se a atingir objetivos diferenciados.

Em nosso estudo sobre a conceituação de interdisciplinaridade, percebemos que esta não apresenta uma definição estável e está associada a diferentes concepções epistemológicas. Observamos que as propostas que buscam fundamentar a interdisciplinaridade na pesquisa científica procuram estabelecer nomenclaturas baseadas em hierarquias, ordenadas em função da complexidade das relações que podem ser estabelecidas entre as disciplinas científicas. Entretanto, estão ligadas a perspectivas epistemológicas diferentes.

A interdisciplinaridade, como entendida no campo da Ciência, não se apresenta como viável de ser implementada na perspectiva educacional, pois, dentre outras características, a concepção de disciplina escolar é diferente da concepção de disciplina científica, e os objetivos da disciplina escolar também o são em relação às 
disciplinas científicas. Disso decorre a inadequação da simples transferência de referenciais teórico-metodológicos daquela para a fundamentação desta última.

A distinção quanto às práticas interdisciplinares - científica e escolar - permitiu a visualização de aspectos característicos relevantes da interdisciplinaridade escolar, como a possibilidade de articulação das disciplinas em uma abordagem relacional; o respeito às suas especificidades e o estabelecimento de ligações de complementaridade e de integração.

Esses aspectos forneceram elementos que nos permitiram analisar propostas que se destinam-se a implementar essa prática interdisciplinar na Educação Escolar e apresentaram um embasamento necessário para uma proposta pedagógica para o Ensino de Ciências e de Matemática no Ensino Médio, ao qual poucas pesquisas têm sido dedicadas.

Uma das formas de conceber uma ação interdisciplinar, que se mostrou em consonância com nossa compreensão de organização dessa prática educativa - relacional e que possibilite ligações de complementaridade e integração de aprendizagens e saberes - foi sistematizada por Lenoir (1998), e compreende uma articulação entre duas ou mais disciplinas escolares nos níveis curricular, didático e pedagógico.

Para além de uma forma de organização, investigamos perspectivas que fundamentam a adoção de práticas educativas interdisciplinares. Dentre essas perspectivas, destacamos os trabalhos de Batista e Salvi (2006) e Fourez, Englebert-Lecompte e Mathy (1997).

Com base nos estudos realizados por Batista e Salvi (2006), percebemos que a ação educativa interdisciplinar é entendida como participante de uma estrutura curricular disciplinar e organizada em momentos interdisciplinares inseridos no processo de ensino e de aprendizagem, não desconsiderando a importância das análises disciplinares, mas reforçando a necessidade de uma integração que contemple os aspectos relacionais presentes no conhecimento escolar.

Em Fourez, Englebert-Lecompte e Mathy (1997), identificamos características relevantes, como: a fundamentação em relação à alfabetização científica e tecnológica e a perspectiva metodológica de construção das ilhas interdisciplinares de racionalidade. Esses aspectos se destacam, sobretudo, em função da orientação construtivista presente nos procedimentos metodológicos adotados junto aos alunos.

Analisando a proposta de trabalho interdisciplinar de Santomé (1998), a experiência realizada na cidade de São Paulo e o Projeto Escola Plural, percebemos que elas, mesmo apresentando possibilidades de implementação e uma organização de qualidade, exigiriam alterações significativas e que implicariam uma reestruturação curricular abrangente que não mostra uma boa adaptabilidade na atual estrutura do Ensino Médio.

A análise de propostas e experiências de implementação nos permitiu identificar diferenças significativas quanto aos respectivos fundamentos educacionais adotados, implicando a adoção de práticas interdisciplinares com vistas ao atendimento de objetivos formativos distintos e, por vezes, inconciliáveis entre elas. Assim, notamos uma diferenciação em relação ao entendimento da interdisciplinaridade, que engloba desde a inserção de momentos interdisciplinares na estrutura curricular atual até propostas que visam construir um currículo integrado, com características transdisciplinares.

Essas considerações nos permitiram delinear um posicionamento quanto à implementação de ações interdisciplinares, para o Ensino de Ciências e de Matemática na Escola Média, que demonstrem cuidados a respeito da organização do espaço e do tempo escolares, 
Interdisciplinaridade em ensino de Ciências e Matemática...

da estrutura curricular e dos recursos geralmente disponíveis, para que se tornem factíveis e estáveis nos currículos do Ensino Médio.

Finalmente, destacamos a necessidade de que os cursos de formação (inicial ou em serviço) de professores de Ciências e de Matemática levem em consideração as características de um ensino interdisciplinar, que implementem medidas que possibilitem a formação de profissionais reflexivos e dêem maior ênfase à condução do processo de ensino e de aprendizagem de forma significativa, com abertura para o trabalho em equipes interdisciplinares. ${ }^{3}$

\section{Referências}

BATISTA, I. L.; SALVI, R. F. Perspectiva pós-moderna e interdisciplinaridade educativa: pensamento complexo e reconciliação integrativa. Ensaio, Belo Horizonte, v. 8, n. 2, p. 147159, 2006.

; LAVAQUI, V. A interdisciplinaridade e o trabalho com projetos no ensino de ciências e de matemática na Escola Média. In: ENCONTRO NACIONAL DE DIDÁTICA E PRÁTICA DE ENSINO, 12, 2004, Curitiba. Anais... Curitiba, 2004. Painel aberto, p. 3766-3780.

BELO HORIZONTE. Secretaria Municipal de Educação. Proposta político-pedagógica: rede municipal de educação de Belo Horizonte. Belo Horizonte, 2002. Disponível em: $<$ http://www.prata.pbh.gov.br/pbh/ index.html?id_conteudo=1920\&id_nivel1=1\&ver_servico=N>. Acesso em: 7 fev. 2003.

DELIZOICOV, D.; ZANETIC, J. A proposta de interdisciplinaridade e o seu impacto no ensino municipal de $1^{\circ}$ grau. In: PONTUSCHKA, N. N. (Org.). Ousadia no diálogo: a interdisciplinaridade na escola pública. São Paulo: Loyola, 1993. p. 9-15.

FAZENDA, I. C. A. Interdisciplinaridade: história, teoria e pesquisa. 2. ed. Campinas: Papirus, 1995.

Integração e interdisciplinaridade no ensino brasileiro: efetividade ou ideologia. 2. ed. São Paulo: Edições Loyola, 1992.

FOUREZ, G. Alfabetización científica y tecnológica: acerca de las finalidades de la enseñanza de las ciencias. Buenos Aires: Ediciones Colihue, 1997.

A construção das ciências: introdução à filosofia e à ética das ciências. São Paulo: Editora da Unesp, 1995.

${ }^{3}$ A esse respeito, sugerimos a leitura dos resultados de pesquisa de Ohira e Batista (2005). 
Lavaqui, V.; Batista, I. L.

.; ENGLEBERT-LECOMPTE, V.; MATHY, P. Saber sobre nuestros saberes: um léxico epistemológico para la enseñanza. Buenos Aires: Ediciones Colihue, 1997.

JAPIASSU, H. Interdisciplinaridade e patologia do saber. Rio de Janeiro: Imago, 1976.

KLEIN, J. T. Ensino interdisciplinar: didática e teoria. In: FAZENDA, I. C. A. (Org.).

Didática e interdisciplinaridade. Campinas: Papirus, 1998. p. 109-132.

LEITE, L. H. A. Pedagogia de projetos. Revista Presença Pedagógica, Belo Horizonte, v. 2, n. 8, p. 25-33, 1996.

LENOIR, Y. Três interpretações da perspectiva interdisciplinar em educação em função de três tradições culturais distintas. Revista E-Curriculum, PUCSP, São Paulo, v. 1, n. 1, 2005. Disponível em: <http://www.pucsp.br/ecurriculum>. Acesso em: 01 mai. 2007.

Didática e interdisciplinaridade: uma complementaridade necessária e incontornável. In: FAZENDA, I. C. A. (Org.). Didática e interdisciplinaridade. Campinas: Papirus, 1998. p. 45-75.

.; LAROSE, F. Uma tipologia das representações e das práticas da interdisciplinaridade. Revista Brasileira de Estudos Pedagógicos, Brasília, v. 79, n. 192, p. 49-59, 1998.

MORIN, E. Ciência com consciência. Rio de Janeiro: Bertrand Brasil, 1996.

OHIRA, M. A.; BATISTA, I. L. Formação inicial de professores para a interdisciplinaridade escolar. In: ENCONTRO NACIONAL DE PESQUISA EM EDUCAÇÃO EM

CIÊNCIAS, 5., 2005, Bauru. Atas... Bauru, 2005. 1-12p.

PALMADE, G. Interdisciplinaridade e ideologias. Madrid: Narcea, 1979.

PERNAMBUCO, M. M. C. A. Significações e realidade: conhecimento. In:

PONTUSCHKA, N. N. (Org.). Ousadia no diálogo: a interdisciplinaridade na escola pública. São Paulo: Loyola, 1993. p. 67-92.

SAMPAIO, M. M. F.; QUADRADO, A. D.; PIMENTEL, Z. P. Interdisciplinaridade no município de São Paulo. Brasília: INEP, 1994.

SANTOMÉ, J. T. Globalização e interdisciplinaridade: o currículo integrado. Porto Alegre: Artes Médicas, 1998.

Artigo recebido em fevereiro de 2007 e aceito em outubro de 2007. 